\title{
THE EFFECT OF LUNASIN ON LIVER HISTOPATHOLOGY OF MICE INDUCED BY AZOXIMETHANE (AOM) AND DEXTRAN SODIUM SULPHATE (DSS)
}

\author{
KUSMARDI ${ }^{1}$, HERIYANTO KHIPUTRA ${ }^{2}$, SALINAH ${ }^{1^{*}}$
}

1Department of Anatomical Pathology, Faculty of Medicine, Universitas Indonesia, ${ }^{2}$ Faculty of Medicine, Universitas Indonesia

Email: salinahsyarif@gmail.com

Received: 12 Dec 2018, Revised and Accepted: 10 Mar 2019

\begin{abstract}
Objective: Azoximethane (AOM) and dextran sodium sulfate (DSS) are commonly used to induce colorectal cancer, but have side effects on the liver. AOM can induce hepatic histopathological changes such as the appearance of microvesicular steatosis and necrosis. DSS plays a role in causing inflammation and indirect scarring through colitis. This study aimed to determine in mice the effect of lunasin on the liver histopathology induced by AOM and DSS.
\end{abstract}

Methods: This was an experimental study conducted in BALB/c mice. The data analyzed were the results of quantification of foci of necrosis, steatosis, and dysplasia from liver preparations of mice given lunasin extract at doses of 20, 30, and $40 \mathrm{mg} / \mathrm{kg}$ and control group.

Results: This study showed a significant decrease in the number of foci of necrosis in the group given $30 \mathrm{mg} / \mathrm{kg}$ lunasin, with a mean score of $9.0 \pm 3.4$ compared with the control group mean score of $14.0 \pm 0.8(P=0.017)$. There was also a significant decrease in the number of foci of steatosis in the group given $30 \mathrm{mg} / \mathrm{kg}$ lunasin with a mean score of $3.8 \pm 1.3$ compared with the control group mean score of $11.5 \pm 1.9(P=0.002)$.

Conclusion: The results of this study indicate that lunasin at doses above $30 \mathrm{mg} / \mathrm{kg}$ can inhibit the formation of foci of necrosis and steatosis induced in mouse liver by AOM and DSS.

Keywords: Azoxymethane, Dextran sodium sulfate, Liver, Mice, Lunasin

(C) 2019 The Authors. Published by Innovare Academic Sciences Pvt Ltd. This is an open access article under the CC BY license (http://creativecommons. org/licenses/by/4. 0/) DOI: http://dx.doi.org/10.22159/ijap.2019.v11s6.33552

\section{INTRODUCTION}

Colorectal cancer is the third most commonly diagnosed cancer in men and the second most common in women. It accounts for over $9 \%$ of all cancer incidence, with an estimated 1.4 million cases occurring in $2012[1,2]$.

Azoximethane (AOM) and dextran sodium sulfate (DSS) are commonly used to induce colorectal cancer in experimental models, but these substances have side effects on the liver. In studies using mice, it was found that AOM can induce hepatic histopathological changes such as the appearance of microvesicular steatosis, necrosis, and the growth of tumor nodules $[3,4]$. DSS plays a role in causing inflammation and indirect scarring through colitis [5].

Lunasin is a chemical contained in soybeans that is considered to have anticancer effects. Lunasin has been demonstrated to prevent several types of cancer, including breast cancer, colon cancer, leukemia, and prostate cancer [6]. In addition to cancer, other diseases that cause damage through inflammation can be suppressed by lunasin because it affects the inflammatory and oxidative pathways that are risk factors for liver damage [6]. Lunasin has the ability to reduce proinflammatory gene expression through modulation of nuclear factor (NF)- $\kappa B$ [7].

There are few studies examining the effect of lunasin on changes in liver histopathology in experimental animals. Although soybean production in Indonesia is still relatively low compared with that in other soybean-producing countries, Indonesia pays special attention to soybeans as a food crop [8]. This study aimed to analyze the efficacy of lunasin in modulating liver histopathology changes induced by AOM and DSS.

\section{MATERIALS AND METHODS}

This study was previously approved by The Ethic Committee of the Faculty of Medicine, Universitas Indonesia, ethical number 181/UN2. F1/ETIK/2016. This study was performed using 20 male BALB/c mice, $12 \mathrm{w}$ old and weighing \pm 20 grams. Mice were acclimatized for 1 $\mathrm{w}$ before being given $\mathrm{AOM}$ dissolved in $0.9 \% \mathrm{NaCl}$ at a dose of $10 \mathrm{mg}$ per kilogram of body weight intraperitoneally. Mice were given standard feed for $1 \mathrm{w}$ then mineral water containing 2\% DSS every day for $1 \mathrm{w}$. After that, mice in the test groups were given lunasin at varying doses every day for $6 \mathrm{w}$. The mice were then sacrificed, and the right lobe of the liver was embedded in paraffin. Slices of liver tissue $4 \mu \mathrm{m}$ thick were stained with hematoxylin and eosin.

The mice were divided into four groups: a control group that was not given lunasin, a group given $20 \mathrm{mg} / \mathrm{kg}$ body weight lunasin (low dose), a group given $30 \mathrm{mg} / \mathrm{kg}$ body weight lunasin (moderate dose), and a group given $40 \mathrm{mg} / \mathrm{kg}$ body weight lunasin (high dose). The independent variable in this study was the dose of lunasin given to the mice. The dependent variable was the number of foci of necrosis, steatosis, and dysplasia.

This experimental study analyzed data from quantification of the number of foci of necrosis, steatosis, and dysplasia in mouse liver observed by light microscopy at 400× magnification. Quantification was performed by assessing 10 fields of view and summing the results. The data obtained in this study were processed using SPSS for Windows (SPSS) v. 20, the Shapiro-Wilk test for the normality of data distribution, and the Levene test for the homogeneity of variance. If the data distribution was normal and homogeneous, then the data were analyzed by a one-way analysis of variance (ANOVA) and Tukey's honest significant difference (HSD) test. If the data distribution was not normal or homogeneous, then the data were analyzed with the Kruskal-Wallis test and the Games-Howell test.

\section{RESULTS}

During the study, one mouse from the control group died. The number of foci of necrosis and the mean for each group are listed in table 1 . The results of the Shapiro-Wilk test and the Levene test showed normal data distributions and homogeneous variances. One-way ANOVA produced $P$ $=0.005$. The results of Tukey's HSD test showed that there were significant differences between the control group and the moderate-and high-dose groups, with a mean score of $14.00 \pm 0.82$ for the control group compared with a mean score of $9.00 \pm 3.39$ for the moderate-dose group $(P=0.017)$ and of $8.20 \pm 1.64$ for the high-dose group $(P=0.009)$. There was no significant difference between the control group and the lowdose group, which had a mean score of $11.60 \pm 1.67(P=0.379)$. 
Table 1: Number of foci of necrosis

\begin{tabular}{lllll}
\hline Sample & Control & $\mathbf{2 0} \mathbf{~ m g} / \mathbf{k g}$ lunasin & $\mathbf{3 0 ~} \mathbf{~ g} / \mathbf{k g}$ lunasin & $\mathbf{4 0} \mathbf{~ m g} / \mathbf{k g}$ lunasin \\
\hline 1 & 15 & 9 & 4 & 6 \\
2 & 14 & 13 & 9 & 9 \\
3 & 14 & 13 & 13 & 9 \\
4 & 13 & 12 & 8 & 7 \\
5 & $0 ?$ & 11.6 & 11 & 8.2 \\
Mean & 14 & & 9 & \\
\hline
\end{tabular}

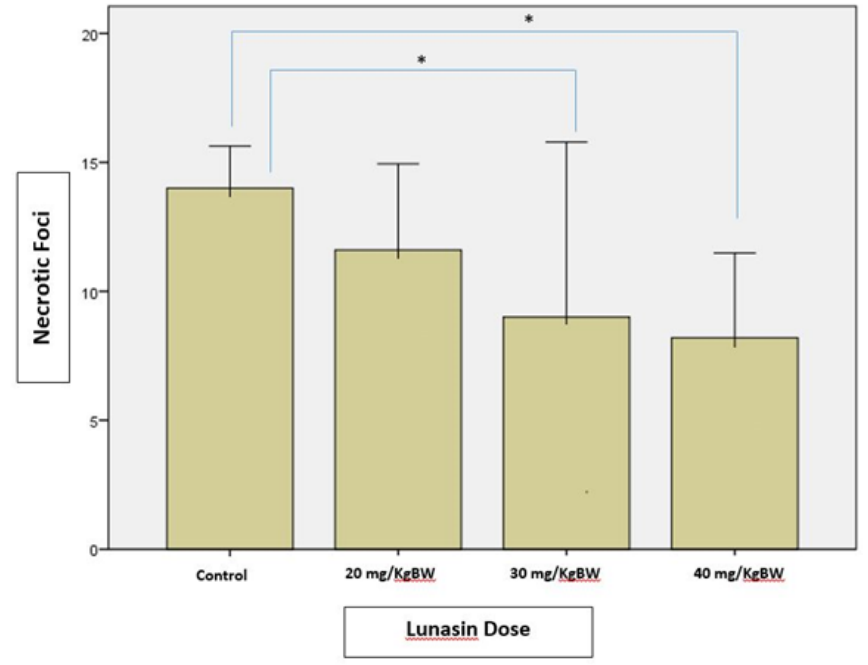

Fig. 1: The effect of various doses of lunasin on the number of hepatic foci of necrosis
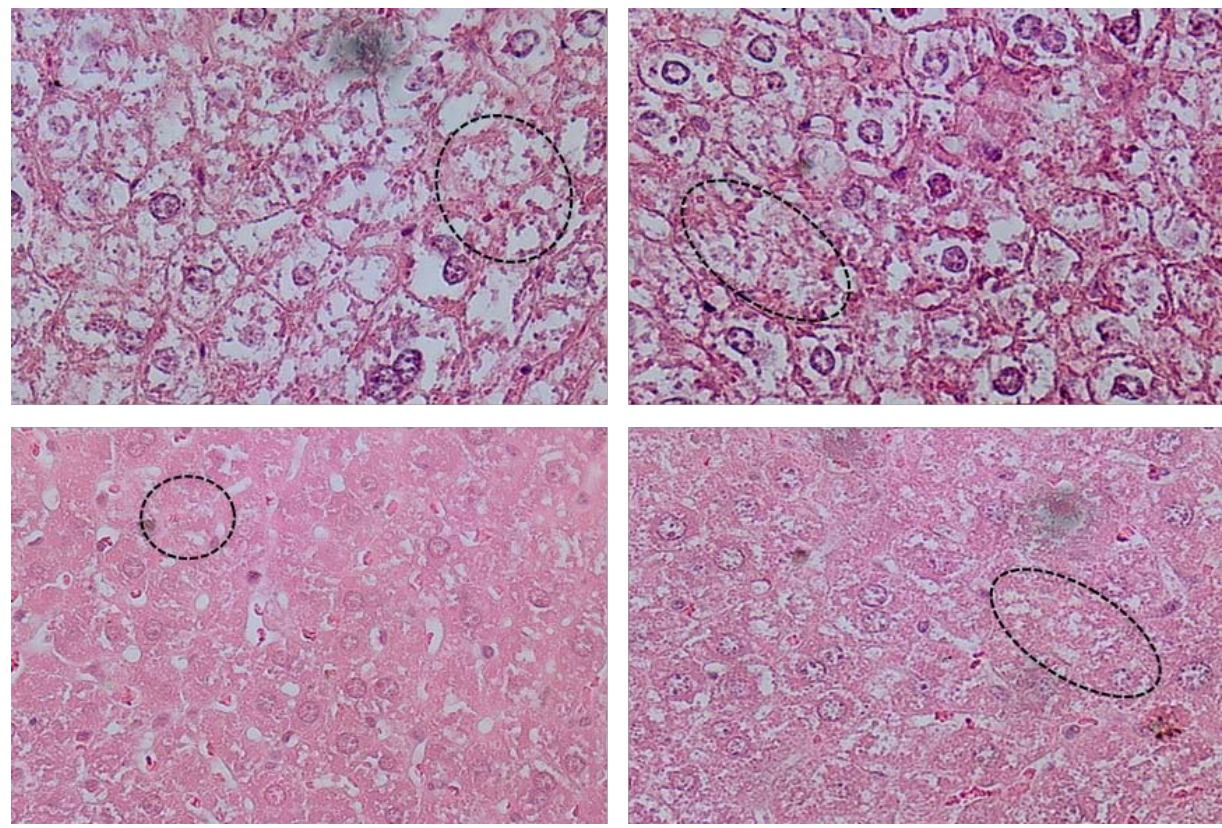

Fig. 2: Histopathological features of foci of liver necrosis. Hematoxylin and eosin staining, 400x (A). Control, (B). $20 \mathrm{mg} / \mathrm{kg} \mathrm{lunasin,} \mathrm{(C).} 30$ $\mathrm{mg} / \mathrm{kg}$ lunasin, (D). $40 \mathrm{mg} / \mathrm{kg}$ lunasin

The mean number of foci of steatosis in each group is shown in table 2 . The results of the Shapiro-Wilk test demonstrated normal data distributions, but the results of the Levene test showed that the intergroup variance was not homogeneous. The results of the Kruskal-Wallis test on the foci of steatosis obtained $P=0.002$. The Games-Howell test showed a significant difference between the control, moderate and high doselunasin-treated groups, with a mean of $11.50 \pm 1.92$ for the control group, $3.80 \pm 1.30$ for the moderatedose group $(P=0.004)$, and $5.20 \pm 2.05$ for the high-dose group $(P=$ 0.009). There was no significant difference between the control group and the low-dose lunasin group, which had a mean of $8.00 \pm 0.71(P=0.091)$. 
Table 2: Number of foci of steatosis

\begin{tabular}{|c|c|c|c|c|}
\hline Sample & Control & $20 \mathrm{mg} / \mathrm{kg}$ lunasin & $30 \mathrm{mg} / \mathrm{kg}$ lunasin & $40 \mathrm{mg} / \mathrm{kg}$ lunasin \\
\hline 1 & 14 & 8 & 6 & 3 \\
\hline 2 & 10 & 7 & 4 & 6 \\
\hline 3 & 12 & 8 & 3 & 7 \\
\hline 4 & 10 & 9 & 3 & 7 \\
\hline 5 & - & 8 & 3 & 3 \\
\hline Mean & 11.5 & 8 & 3.8 & 5.2 \\
\hline
\end{tabular}

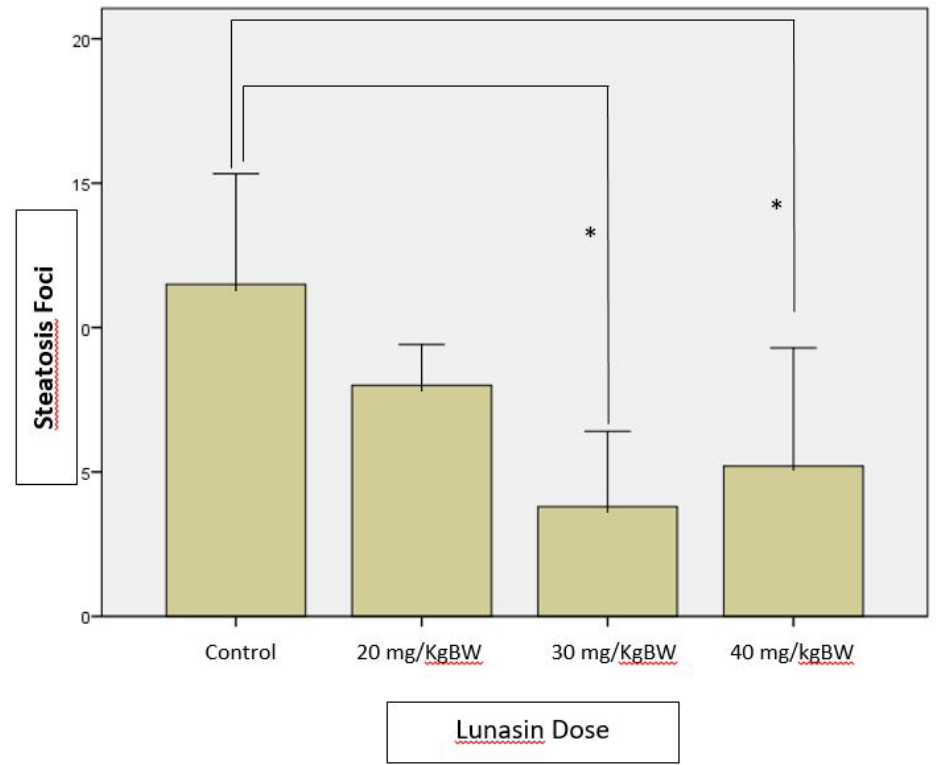

Fig. 3: The effect of various doses of lunasin on the number of hepatic foci of steatosis
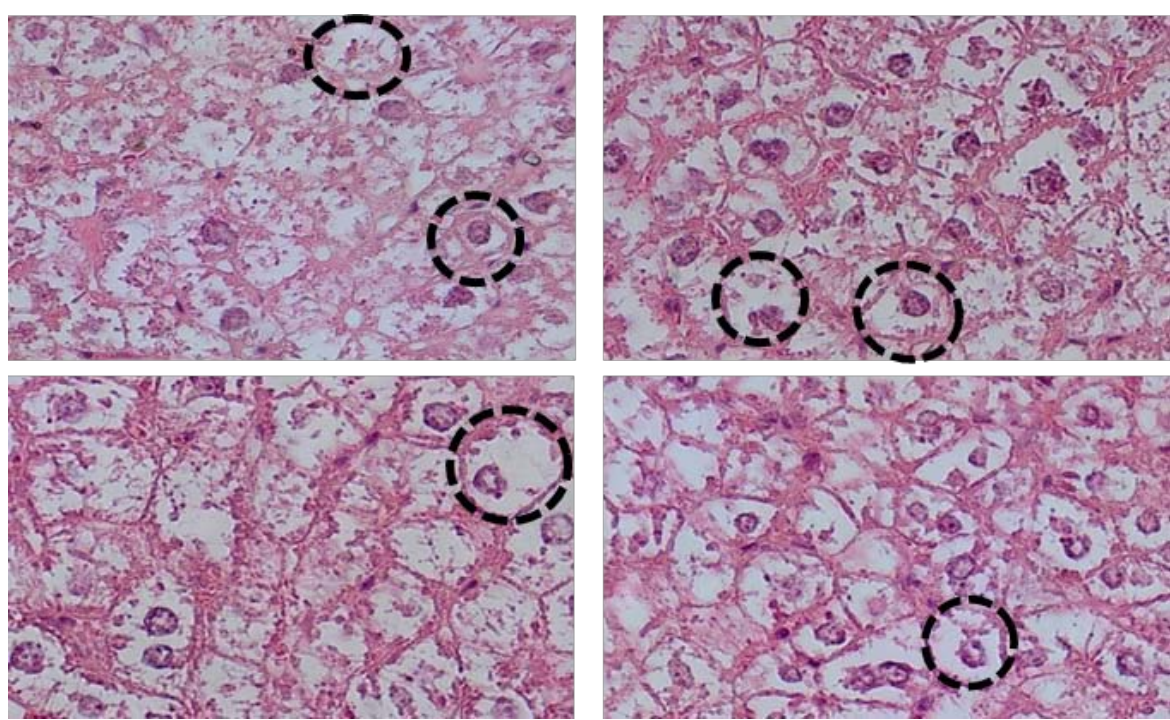

Fig. 4: Histopathological features of the foci of liver steatosis. Hematoxylin and eosin staining, 400x (A). Control, (B). $20 \mathrm{mg} / \mathrm{kg}$ lunasin, (C). $30 \mathrm{mg} / \mathrm{kg}$ lunasin, (D). $40 \mathrm{mg} / \mathrm{kg}$ lunasin, No dysplasia induced by AOM and DSS was observed in any mouse liver preparation.

\section{DISCUSSION}

Observations showed that the number of foci of necrosis was reduced with increasing doses of lunasin. From the results of the analysis, it can be seen that there is a significant difference between the control group and the groups given lunasin at doses of 30 and $40 \mathrm{mg} / \mathrm{kg}$, although there was no significant difference between the control group and the low-dose group. The effect of lunasin on the development of foci of necrosis has not been reported previously, but it has been reported that lunasin can inhibit the production of tumor necrosis factor $\alpha$ and interleukin-6 in RAW264 cells [8] stimulated by lipopolysaccharide and Akt-mediated activation of NF- $\mathrm{KB}[9,10]$.

The results also showed that the number of foci of steatosis decreased significantly following the administration of lunasin at doses of 30 and $40 \mathrm{mg} / \mathrm{kg}$. The identification of foci of steatosis is consistent with the report by Burlamaqui et al., who found steatosis in the liver of mice given $15 \mathrm{mg} / \mathrm{kg} \mathrm{AOM}$ injected once a week [11]. The mechanism by which lunasin reduces the number of foci of steatosis is unknown, but is likely to be related to the cytoprotective 
effect of lunasin resulting from a reduction in the level of free-radical reactive oxygen species production and an increase in the production of glutathione (GSH) [12]. Free radicals are one indicator of mitochondrial damage that can lead to steatosis [13], and GSH is a major antioxidant enzyme that is important in counteracting free radicals. However, studies conducted by Fernandez-Tome et al. found that the decrease in free radicals and increased GSH levels did not depend on the dose of lunasin [12]. There were no foci of dysplasia detected in any liver preparations. This is consistent with the results of a study by Karlsson et al. [11], which showed that administration of 2.5\% DSS to mice altered liver function but produced no detectable histopathological abnormalities [14]. The present study used 2\% DSS solution, slightly weaker than that used by Karlsson et al., but their results indicate that the lack of dysplasia seen in the present study was not because of the lack of a higher DSS dose. Another explanation is that the dose of AOM used in this study $(10 \mathrm{mg} / \mathrm{kg})$ was not high enough to cause hepatic failure, which Burlamaqui et al. reported generally requires $50-100 \mathrm{mg} / \mathrm{kg}$ [11]. The effect of lunasin on the number of foci of dysplasia in the liver of mice is unknown because this study did not find any in the control or treated groups.

\section{CONCLUSION}

Injection of $10 \mathrm{mg} / \mathrm{kg} \mathrm{AOM}$ and $2 \%$ DSS can cause necrosis and steatosis but not dysplasia in mouse hepatocytes. Lunasin at doses of $30 \mathrm{mg} / \mathrm{kg}$ and above can significantly inhibit the formation of focal necrosis and steatosis.

\section{ACKNOWLEDGMENT}

This article was presented at the $3^{\text {rd }}$ International Conference and Exhibition on Indonesian Medical Education and Research Insitute (ICE on IMERI 2019), Faculty of Medicine, Universitas Indonesia, Jakarta, Indonesia. We would like to thank the Ministry of Research, Technology, and Higher Education for a PUPT 2018 and Directorate of Research and Public Services of Ministry of Sains, Technology, and Higher Education, Republik Indonesia. We thank the $3^{\text {rd }}$ ICE on IMERI Committee who had supported the peer review and manuscript preparation before submitting to the journal.

\section{AUTHORS CONTRIBUTIONS}

All the author have contributed equally

\section{CONFLICT OF INTERESTS}

We have no conflict of interest to declare

\section{REFERENCES}

1. Torre LA, Bray F, Siegel RL, Ferlay J, Lortet Tieulent J, Jemal A. Global cancer statistics. CA Cancer J Clin 2012;65:87-108.
2. Ferlay J, Shin HR, Bray F, Forman D, Mathers C, Parkin DM. Estimates of worldwide burden of cancer in 2008:GLOBOCAN 2008. Int J Cancer 2008;127:2893-917.

3. Matkowskyj KA, Marrero JA, Carroll RE, Danilkovich AV, Green RM, Benya RV. Azoxymethane-induced fulminant hepatic failure in C57BL/6J mice: characterization of a new animal model. Am J Physiol-Gastrointest Liver Physiol 1999;277:G455-G462.

4. Nozaki T, Fujihara $H$, Watanabe $M$, Tsutsumi M, Nakamoto $K$, Kusuoka 0, et al. Parp-1 deficiency implicated in colon and liver tumorigenesis induced by azoxymethane. Cancer Sci 2003;94:497-500.

5. Gäbele E, Dostert K, Hofmann C, Wiest R, Scholmerich J, Hellerbrand C, et al. DSS induced colitis increases portal LPS levels and enhances hepatic inflammation and fibrogenesis in experimental NASH. J Hepatol 2011;55:1391-9.

6. Hernandez Ledesma B, de Lumen BO, Hsieh CC. 1997-2012: fifteen years of research on peptide lunasin. In: Hernndez Ledesma B. editor. Bioactive Food Peptides in Health and Disease [Internet]. InTech; 2013. Available from: http://www.intechopen.com/books/bioactive-food-peptidesin-health-and-disease/1997-2012-fifteen-years-of-researchon-peptide-lunasin. [Last accessed 20 Dec 2015]

7. de Mejia EG, Dia VP. Lunasin and lunasin-like peptides inhibit inflammation through suppression of NF-KB pathway in the macrophage. Peptides 2009;30:2388-98.

8. Adetama D. Analisis permintaan kedelai di indonesia periode 1978-2008. [Jakarta]: Universitas Indonesia; 2011.

9. Hernández Ledesma B, Hsieh CC, de Lumen BO. Antioxidant and anti-inflammatory properties of cancer preventive peptide lunasin in RAW 264.7 macrophages. Biochem Biophys Res Commun 2009;390:803-8.

10. Cam A, de Mejia EG. RGD-peptide lunasin inhibits Akt-mediated $\mathrm{NF}-\mathrm{KB}$ activation in human macrophages through interaction with the $\alpha$ V $\beta 3$ integrin. Mol Nutr Food Res 2012;56:1569-81.

11. Burlamaqui IMB, Dornelas CA, Almeida PRC, Jamacaru FVF, Mota DMC, Mesquita FJC, et al. Hepatic repercussions of azoxymethane-induced colorectal carcinogenesis. Rev Colegio Bras Cir 2013;40:137-41.

12. Fernandez Tome S, Ramos S, Cordero Herrera I, Recio I, Goya L, Hernandez Ledesma B. In vitro chemoprotective effect of bioactive peptide lunasin against oxidative stress in human HepG2 cells. Food Res Int 2014;62:793-800.

13. Browning JD, Horton JD. Molecular mediators of hepatic steatosis and liver injury. J Clin Invest 2004;114:147-52.

14. Karlsson A, Jagervall A, Pettersson M, Andersson AK, Gillberg PG, Melgar S. Dextran sulphate sodium induces acute colitis and alters hepatic function in hamsters. Int Immunopharmacol 2008;8:20-7. 